EPJ Web of Conferences 33, 04009 (2012)

DOI: $10.1051 /$ epjconf/20123304009

(C) Owned by the authors, published by EDP Sciences, 2012

\title{
Application of Hybrid-Electric Power Supply System in Fishing Vessels.
}

\author{
C. Gutiérrez ${ }^{1, a}$ and D. Meana ${ }^{2}$ \\ ${ }^{1}$ EnergyLab Technology Centre, Mobility Area Manager, 36310 Vigo, Spain \\ ${ }^{2}$ EnergyLab Technology Centre, Mobility Area Researcher, 36310 Vigo, Spain
}

\begin{abstract}
In a clear commitment for sustainability in the fisheries sector, Regional Administration for Economy and Industry of Xunta de Galicia and EnergyLab Technology Centre signed a cooperation agreement with the goal of performing a demonstration project based on the application of hybrid power supply systems in a fishing vessel. Such a project aims to analyze the feasibility of implementing hybridelectric powertrain systems in the Galician coastal fleet. The final purpose is the implementation of more efficient and environmental friendly propulsion systems within the marine industry. The project scope consists in defining a technical solution for the replacement of diesel propulsion system in a standard fishing vessel (12m. long), representative of the Galician inshore fleet, by a hybrid-electric system powered by three different types of energy sources.
\end{abstract}

\section{Goal}

Main goal of the project is to define an alternative electro-mechanical power supply plant for coastal fishing vessels, able to reduce noise, vibrations, greenhouse emissions and environmental hazard in case of spilling; in summary, more bio-friendly.

\section{Project Scope}

1. In first step, the boat is portrayed by its general main dimensions and hull shape. With such information the drag curves of the boat are obtained through by CFD modelling and

2. With such information, and together with a defined operating protocol and classic calculation methods, the energy needs of the ship are sized up.

3. Afterwards the self-regulated hybrid-electric power supply system is defined in detail, reaching a compromise between power and autonomy.

4. Next topic is to provide the boat with a system of monitoring and data acquisition able to give back needed information to run the power supply system in the safest and most efficient way.

5. Further on, the equipment distribution on board is set up by iterative process, crosschecked with stability calculations until the best balanced solution possible comes up.

\footnotetext{
a e-mail : carlos.gutierrez@energylab.es
} 


\section{Introduction}

Costs reduction is a must in marine sector due to market evolution in these latest years. The price of catches drops daily meanwhile the fuel price raises parallel, so the profit of fishing activity is becoming less at the point of being untenable. This situation brings out the need of acting over both two parameters: cost reductions and catches increases. The project approach faces the substitution of propulsion system based on diesel engines by another one quieter, more environmental friendly and less petrol-price dependant. The solution defined with such a goal is a hybrid-electric propulsion system feed by three different energy sources: grid incoming electric energy stored onboard in Lithium cells, hydrogen stored onboard in high pressure bottles and auxiliary diesel engine driving an electric generator. Last two types of energy are transformed in electric power by a fuel cell and an electric generator respectively, while the first is consumed directly as it's stored.

Looking at the Register of Galician Fishing Vessels (data from 2009)[1] the type of target boat was selected trying to achieve the highest scope of influence, so the bigger is the potential market the more diluted would be the costs. With such an approach it was found out that almost five thousands of fishing vessels, only in the Galician region, were listed as less powerful than 100HP and length shorter than $18 \mathrm{~m}$. It supposes round about the $85 \%$ of the whole fleet registered, so those were chosen as target vessels.

The Galician Coastguard Service hands over an existing auxiliary boat within such a type of vessel as sample for refurbishing.

Main features of that vessel are:

Table 1. Vessel Main Features.

\begin{tabular}{|l|l|}
\hline \multicolumn{1}{|c|}{ Dimension } & \multicolumn{1}{c|}{ Units } \\
\hline Total Length & $11,2 \mathrm{~m}$. \\
\hline Beam & $4,1 \mathrm{~m}$. \\
\hline Height & $1,8 \mathrm{~m}$. \\
\hline Draft & $1,25 \mathrm{~m}$. \\
\hline Tonnage & $19,5 \mathrm{GT}$. \\
\hline Engine Power Output/Max. Speed & $176 \mathrm{~kW} / 9$ knots. \\
\hline
\end{tabular}

\section{Project Performance}

\subsection{Shape, Dimensions and Stability}

Unfortunately, the handed over boat had not any technical documentation available, further than Marine Ordinary Registration Form, so first task is to beach the vessel in order to draw down precisely the dimensions and shape of the hull (Figure 1), as well as the distribution on different compartments and equipment all inside the boat (Figure 2). 


\section{$2^{\text {nd }}$ European Energy Conference}
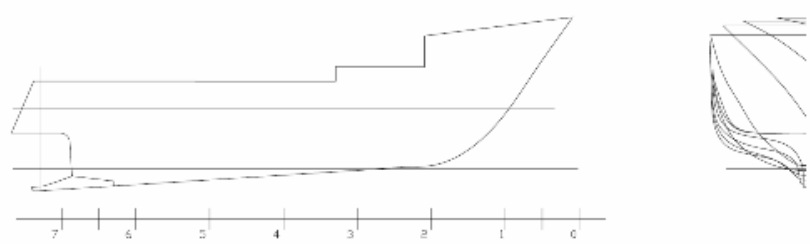

Fig. 1. Hull Shape.

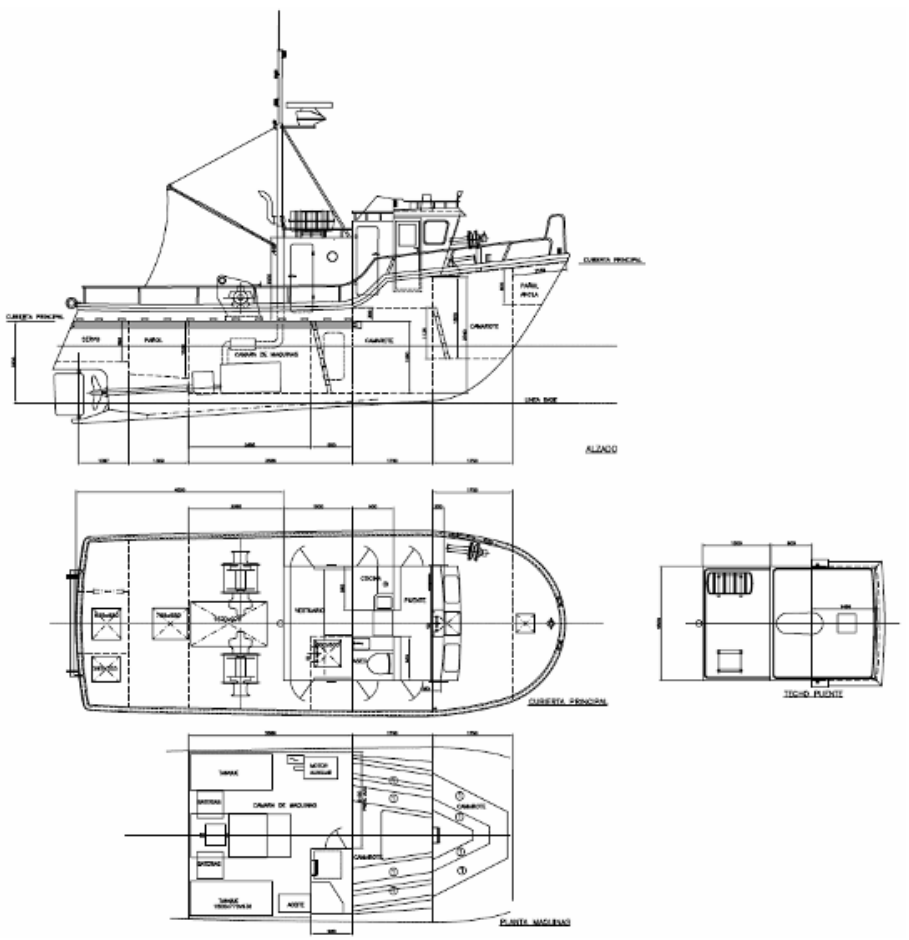

Fig. 2. Vessel Main Drawing.

In this stage, and in order to allow comparing the state before and after the refurbishment, the Stability and Freeboard Study is also done following the content of option 6 of the standard ISO12217-1 for Not Sail Boats longer than 6 meters, in its class of design C. The results obtained are, as expected, within the range required by law.

\subsection{Power Requirement Calculation}

To find out the drag force of the boat a 3D model of the hull is built up and a Computational Fluid Dynamics (CFD) simulation is performed for one single point of the vessel operation map. The ult of such simulation is crosschecked and extended to the whole range of operation speed (Figure 3) through by classic numeric calculation methods (Holtrop, Van Oortmerssen, Digernes \& Yi, Walderaugh). Extreme values are rejected.

An additional method carried out is an on board measure of fuel consumption and rpm's at different crossing speeds, so through by a fast numeric approximation based on the coefficient of performance and energy balance (Ecu. 1) the propulsion power demand $\left(\mathrm{PP}_{\mathrm{D}}\right)$ can be calculated and matches considerably with results of both other methods. 


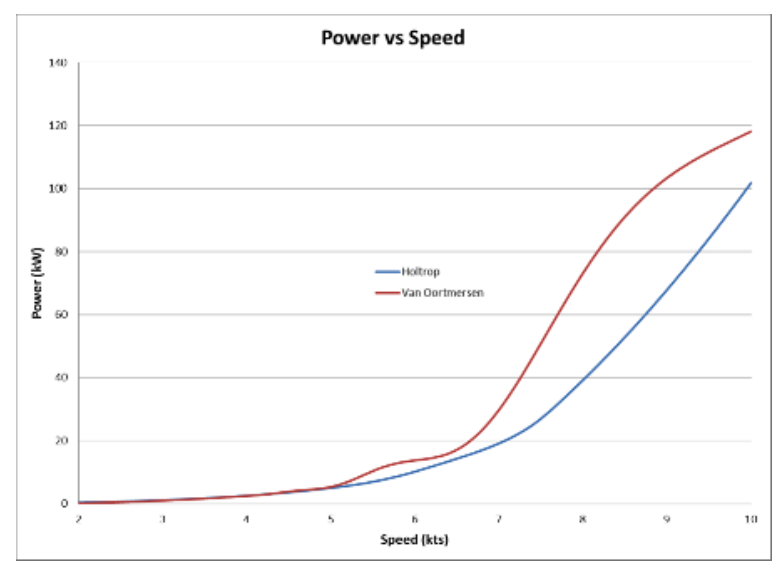

Fig. 3. Propulsion Power demand vs. Speed.

$$
\left.P P_{D}\right]_{t_{0}}^{t_{1}}=P C I \cdot \eta_{E n g} \cdot \eta_{P T} \cdot \int_{t_{0}}^{t_{1}} \frac{\partial M}{\partial t}
$$

- PCI: inferior calorific power of the fuel

- $\eta_{\text {Eng }}$ : engine coefficient of performance

- $\eta_{\mathrm{PT}}$ : powertrain coefficient of performance

- $\partial \mathrm{M} / \partial \mathrm{t}$ : de diesel mass flow

Ecuation (1). Power Plant Energy Balance.

Vessel's maximum speed of operation is 9 knots, so matching with the graph above, the maximum propulsion power required in worst case is $103 \mathrm{~kW}$. The efficiency of that speed parameter will be questioned further on.

An estimation of additional power consumption due to auxiliary equipment (lighting, pumps, Navigation Assistance Equipment, communications, etc.) adds $6 \mathrm{~kW}$ extra to the count, raising it up to $109 \mathrm{~kW}$.

\subsection{Service Requirements}

Real service is determined directly asking the operator, looking into the history of last services done (little and uncompleted information had been recorded) and by a visual inspection of machinery on board.

- From those inputs some considerations regarding operation come out:

- Average duration of one common service and length by mode of sailing were defined.

- Top speed is not mandatory for service.

- Realize that some remaining machinery has never been used as Coastguard Vessel.

Based on that, maximal speed is limited up to 8 knots and longest time per service without refuelling is established in 8 operation hours, split in:

- 2 hours of harbour manoeuvers (<6 knots).

- 2 hours of coasting medium speed (<7 knots).

- 2 hours of coasting at top speed (=8 knots).

- 2 hours of task manoeuvers (<6 knots).

Applying that speed pattern to the propulsion power demand curves drawn before and adding the auxiliaries power consumption with a temporary load factor of 0.5 , an operation and energy consumption pattern is estimated.

\section{Design of Power Supply Plant}

\subsection{Approach}

The refurbishment is commonly more complex than new constructions since the scenario is already drawn and the task is to fit a new concept in the place of existing one keeping some others 


\section{$2^{\text {nd }}$ European Energy Conference}

untouched. In this case there are three main topics which determine the feasibility of substitution and the technology to be installed:

- Real Service defined.

- Limitations coming from free space on board.

- Matching as much as possible the weight to remove and to add.

Those topics are analyzed and fitted together as much as possible in order to find out:

- Proper technology to be used, which will provide the power features demanded by the boat.

- Contribution of each different energy source to the whole power supply.

- The balance between the energy stored on board and its consumption ratio, bringing out the autonomy of the vessel.

The criteria supporting this approach and the whole definition of the plant, especially for the selection of equipment, is mainly based in the from now on called three principal factors:

- Highest efficiency.

- Dimensions and weight.

- Cost.

\subsection{Solution Definition}

The hereon set out engineering project is the given solution to the above described need, in the frame shaped by a refurbishment and fulfilling as much as possible the criteria established.

\subsubsection{Electric Drive \& Motor}

So first of all, using the value obtained for propulsion power requirement $(103 \mathrm{~kW})$ as input, an electric motor is selected. The mentioned three principal factors meet the balance in a $132 \mathrm{~kW}$ 3ph.AC squirrel cage motor, class IE3 Premium Efficiency under IEC60034-30 standard.

\subsubsection{Power Sources Contribution}

To feed such a motor a hybrid-electric power supply system is defined in detail, reaching a compromise between power features, energy storage and operational autonomy.

As told before, primary energy sources are electricity from grid (battery pack), hydrogen (pressured bottles) and diesel (as a subsidiary system). The contribution ratio of each source is determined having in account the following concerns:

I. Hydrogen technology is still in demonstration stage, so it is expensive and its feasibility still has to be proved [2].

II. Lithium batteries are also not so much tested in big powers, but such technology is the only one from the hi-tech scene developed enough that matches with the weigh and space limitation on board.

III. Diesel engine generator is always a grant to move the boat forward in case of failure of new tech or as extra-energy provider when necessary.

Therefore, and once again, matching these concerns with principal factors mentioned before, the power supply is split as follows:

I. Hydrogen Fuel Cells up to $16 \mathrm{~kW}$ : This is the most experimental technology deployed in the project, so such a power meets the balance of available products, costs (technology and operation) and percentage of total power to get representative data.

II. Rechargeable Lithium Battery Pack up to $100 \mathrm{~kW}$ : This is the main source of energy and has to be able to cover the total power demand by itself. So, as the top speed has been limited up 
to 8 knots, total power demand will never exceed theoretical $80 \mathrm{~kW}$. So, applying a safety coefficient of $1.25,100 \mathrm{~kW}$ must be available.

III. Diesel Generator Set up to $35 \mathrm{kVA}$ : Power enough to move the boat forward $(\approx 6 \mathrm{knots})$ to a safe place by itself.

The energy amount to be stored on board is calculated by a tool made in order to define, by an iterative process, the battery cells capacity [3] and the kilograms of $\mathrm{H}_{2}$ needed to fulfil the requirement of the energy consumption pattern. That calculation tool applies performance coefficients, as Peukert and Nominal Discharge Ratio, to match the energy consumption with real value of energy needs. That tool finds the convergence in the final parameters.

\subsubsection{Power Sources Management}

Each energy source has its own delivery features, so they all have to meet a common point to be mixed and managed. To do that, several current and voltage transformations are necessary. The goal is to minimize them, what suppose energy efficiency optimization and failure potential modes minimization. So that, a power management at propulsion full voltage level and in DC mode comes out as best option, since it minimizes number of transformations and avoids the synchronism troubles when electric energy is mixed in AC mode. Therefore some electric conversions have to be done downstream the electric outlet of each energy source to meet the mentioned mixing point. All those transformation are carried out by the set hereinafter called Power Distribution System. It includes also respective safety devices.

In other hand, and once the power balance is set up, the operation management of all three energy sources is defined attending to technical and safety specifications of technologies, operation feasibility and operational costs. The resultant working mode is documented with a block diagram (Figure 8) which will be programed into the controller of the power distribution system.

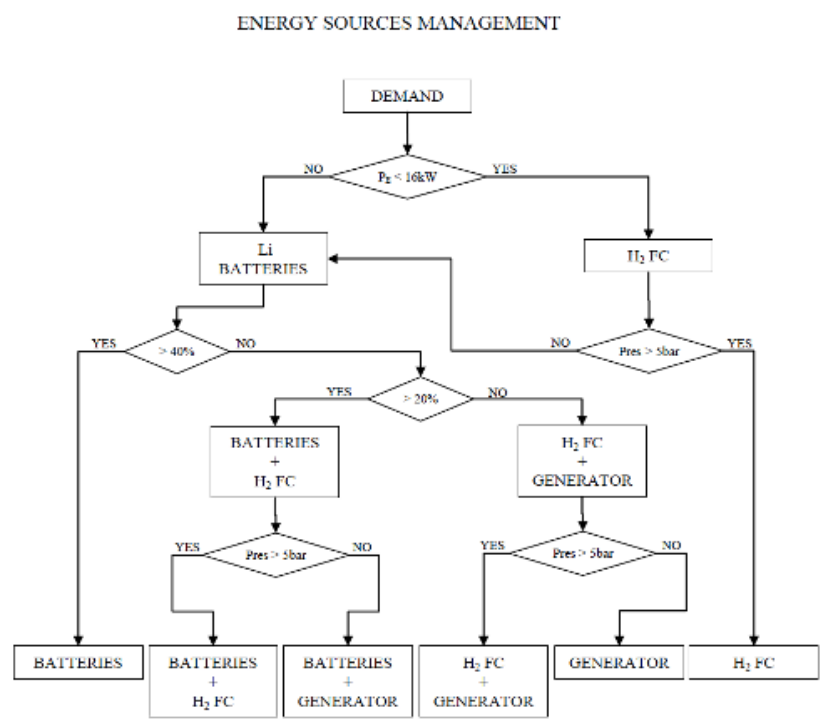

Fig. 8. Energy Sources Management.

An additional function to be done by a second subsystem is to oversee and monitor the whole installation, including following functions:

- Read the value of main operation parameters and match them with established pattern.

- Record continuously these values in a raw data life file. 


\section{$2^{\text {nd }}$ European Energy Conference}

- Interpret collected data in real time and give proper orders to fulfil the working mode determined in the energy sources management diagram and to protect the power plant and the crew against overloads, abnormal or unsafe operation.

One main problem of collecting data in real time is to integrate all communications protocols. In order to solve this problem the Overseeing and Monitoring System will be composed by:

- PLC system: with additionally I/O and Profinet modules, will be in charge of integrate analogic/digital imputs/ouputs, VSD communications and bridge screen control.

- PC: An industrial computer is necessary to integrate and normalize collected data of all systems.

- Gatewey CANopen to SNMP: This system converts CANopen communication protocol to SNMP protocol. This process is necessary to integrate de data collected from Fuel Cell and DC/DC converter.

Both two subsystems together make up the Plant Power Management System.

\subsubsection{Hydrogen System}

- Feeding Method: Hydrogen is stored in three replaceable racks of high pressure bottles installed over the main deck and it is supplied to the fuel cell through by a piping in which pressure and flow are adapted to the fuel cell specs.

- Hydrogen Fuel Cell: Unit based in technology of proton exchange membrane (PEM) is used, delivering direct current (DC) at very low voltage level. Output power up to $16 \mathrm{~kW}$.

- Electric Adjustment: DC-DC voltage elevation up to management level is necessary [4].

\subsubsection{Lithium Batteries System}

- Feeding Method: Lithium Battery Pack is fed directly from a recharging post, located over the harbour dock, connected to common electric power supply grid through by a standard electric hose and plug.

- Lithium Battery Pack: It is built putting together as many single cells, 3.2VDC and 700Ah each, as necessary to cover full power demanded. That means full voltage level in direct current mode (DC).

- Electric Adjustment: No transformation needed in discharge mode, but AC-DC conversion has to be added for charging mode in port.

\subsubsection{Diesel Generator Set}

- Feeding Method: Diesel is stored into a standard reservoir, close to the engine, in the engine room, under the main deck.

- Generator Set: As it has to be able to feed the drive motor directly, is configured to deliver full voltage level at 3 phase alternative current mode (AC) up to $35 \mathrm{kVA}$.

- Electric Adjustment: AC-DC conversion at voltage full level in auxiliary mode. No transformation needed in direct supply mode (when new tech failure happens).

All these Systems and their energy transformations linked together and feeding the drive motor set draw the general electric sketch of power plant (Figure 9).

\subsection{Distribution of Components on board}

Last stage of the engineering project is to design and choose the single components of each system with the main goal of fitting them inside the boat filling up the places of removed material as much 
as possible. This philosophy has as target not to modify so much the original weight distribution of the vessel, so it tries to not move far away from original stability calculations.

Of course, an iterative process is done parallel, where design and distribution of components and stability have to converge fulfilling all the requirements as functional as normative. Final disposition is shown in figure (Figure 10).

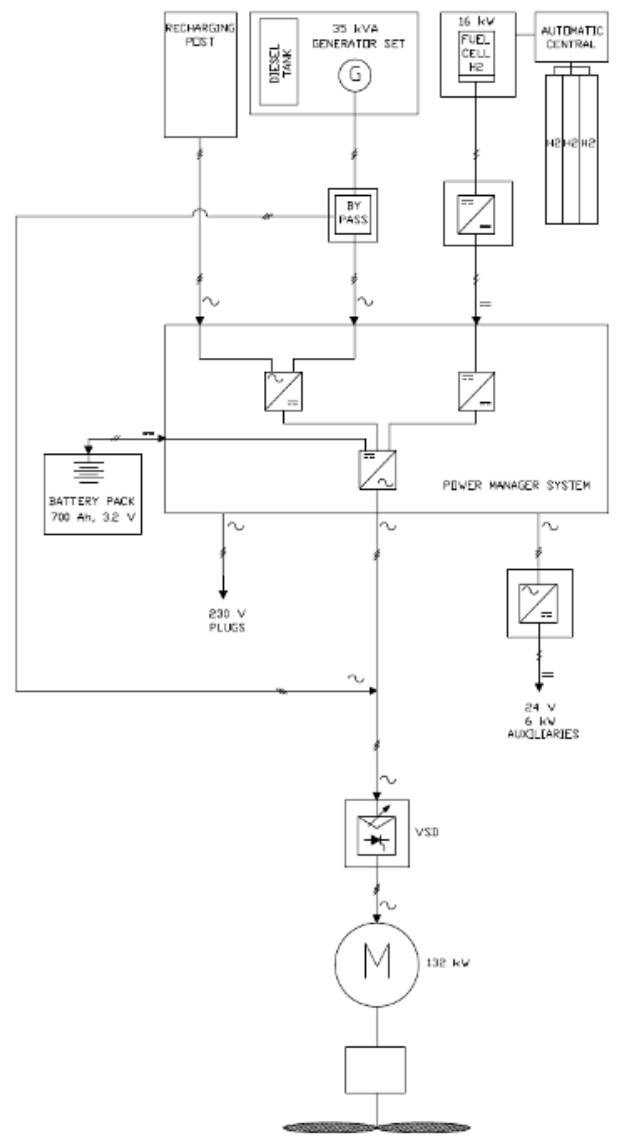

Fig. 9. Power Plant Diagram

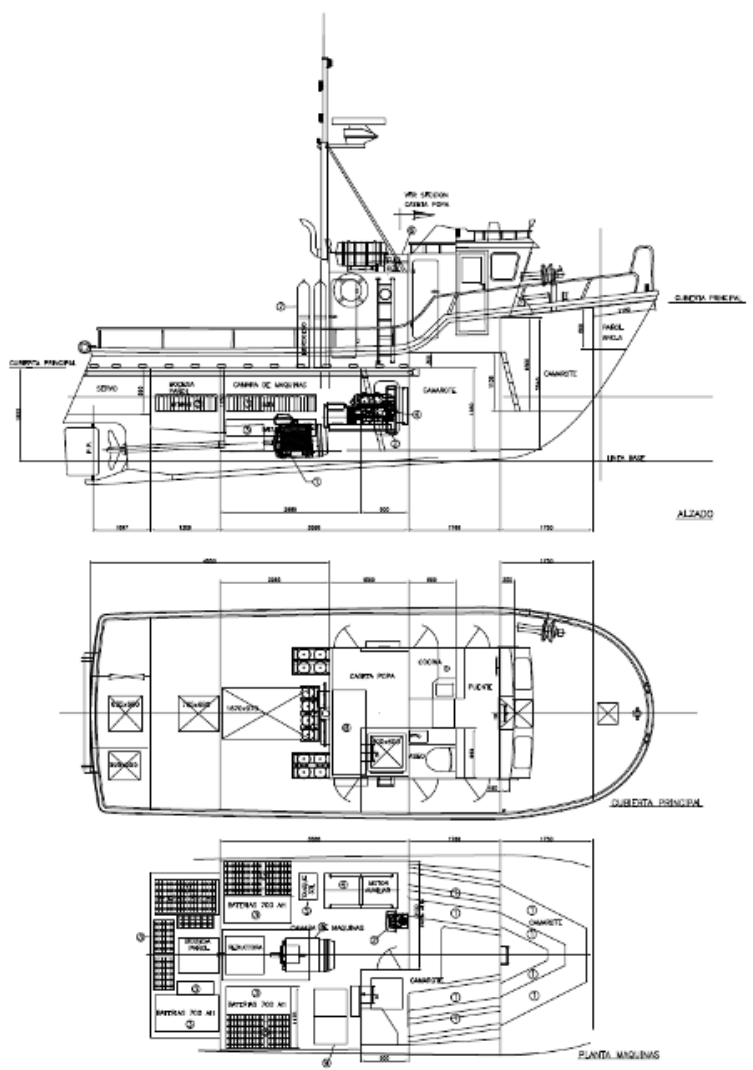

Fig. 10. Refurbished Vessel Main Drawing

\section{References}

1. C. Gabín, V. Rodríguez, M. Blanco, L Rodíguez, F. Taibó and Ch. García, "Rexistro de buques pesqueiros da Comunidade Autonoma de Galicia 2009" Xunta de Galicia, Consellería do Mar, ISBN: 978-84-453-4886-4, D.L. 406-2010.

2. Gijsbert de Jong and Philippe Corrignan, "Guidelines for the safe application of fuel cell systems on ships", Bureau Veritas, Annual Marine Propulsion Conference, London, March 2009.

3. Suleiman Abu-Sharkh and Dennis Doerffel, "Rapid test and non-linear model characterization of solid-state lithium-ion batteries", Journal of Power Sources 130, 2004.

4. D. Vinnikov, T. Jalakas and I. Roasto, "A New High-Power DC/DC Converter for Residential Fuel Cell Power Systems”, Department of Electrical Drives and Power Electronics, Tallinn University of Technology, 2009. 